\title{
Chapter 16 \\ Climate Migration and Cultural \\ Preservation: The Case \\ of the Marshallese Diaspora
}

\begin{abstract}
Alison Heslin
Abstract Potential land loss in Pacific island countries from rising sea levels raises many concerns regarding how nation states will continue to function politically and economically in the event of climate-induced relocation of their populations. This piece expands that conversation, addressing the impacts of relocation on cultural heritage, drawing on data from interviews with migrants from the Marshall Islands to the United States. The study seeks to understand the challenges and opportunities of cultural preservation among the Marshallese diaspora. Marshallese accounts of life in the United States indicate many opportunities for cultural preservation, particularly for those living in communities with large Marshallese populations, while also presenting challenges based on social, economic, and geographic differences between the U.S. and the Marshall Islands. Understanding the means through which Marshallese migrants maintain cultural traditions and the challenges current migrants face, can help us address potentially irreversible, but avoidable losses of cultural traditions in the event of mass displacement.
\end{abstract}

Keywords Cultural heritage $\cdot$ Migration $\cdot$ Non-economic losses $\cdot$ Marshall islands $\cdot$ Diaspora

\subsection{Losses and Damages in the Pacific Islands}

For the low-lying islands of the Pacific, climate change poses an existential risk (see also chapter by Handmer and Nalau 2018). In particular, increased sea level and temperature threatens the islands and atolls with floods, erosion, groundwater degradation, and coral reef damage (Nurse et al. 2014). Under the Representative Concentrations Pathway (RCP) scenarios, by 2100 mean sea levels will increase $0.44 \mathrm{~m}$ (under RCP 2.6) up to $0.74 \mathrm{~m}$ (under RCP8.5) with regional variations that could further increase sea levels in the Pacific (IPCC 2013). Based on these

\footnotetext{
A. Heslin $(\varangle)$

International Institute for Applied Systems Analysis (IIASA), Laxenburg, Austria

e-mail: heslin@iiasa.ac.at 
projections, low-lying islands will be severely negatively affected and uninhabitable, necessitating the relocation of their populations within the next 50 years. These impacts will have economic, political, and cultural consequences for the populations of many Pacific nation-states.

With rising seas and increased sea temperatures, islands face challenges to their economic production. Warmer oceans can damage coral reefs, decreasing tourism and fish production (Asian Development Bank 2013; Rosegrant et al. 2016), and changes in rainfall and salt water inundation can affect fresh water lenses and crop production such as copra and taro (Barnett 2011; Patel 2006; Terry and Chui 2012). Additionally, out-migration from the islands removes higher-skilled laborers from the domestic labour pool (Brown and Connell 2004). Politically, the complete relocation of island populations raises questions of sovereignty. Where will the populations move to, how will their governments function outside their national territory, and what rights will island citizens have in new countries (Barnett and Adger 2003)? The short and medium-term projections of climate change raise many such political and economic questions for islands nations. While the challenges related to economic Loss\&Damage and political sovereignty are indeed severe and worthy of attention, understandings of climate related Loss\&Damage must also take into account non-economic losses, including the effects of climate change on cultural heritage and preservation. Even if existing states agree to host relocated populations, the movement of populations can result in the loss of sacred or culturally significant locations and can affect cultural identity, language, and social structures (see chapter by Serdeczny 2018). Losses of culture or struggles of cultural integration are important for individual and community well-being and can also, in turn, affect the economic and political capacity of the population. Understanding the challenges and opportunities faced by existing Pacific island diasporas offers valuable insight into the potential future of displaced island nations.

\subsection{Methods}

This study seeks to identify the avoidable and unavoidable risks posed to cultural heritage in the event of displacement. To do so, this study draws on in-depth interviews of members of the Pacific Islands diaspora to understand the ways in which they maintain cultural heritage outside of their country of origin. Using the Marshall Islands (Republic of Marshall Islands, RMI) as a case study for potential relocation of populations, interviews were conducted with Marshallese citizens who had migrated to the United States. The participants answered questions regarding what motivated them to move to the United States, what aspects of life differed markedly from the Marshall Islands, and what challenges and opportunities they faced in adapting to living outside of the Marshall Islands. Participants in the interviews were selected through convenience and snowball sampling, ensuring to include participants from multiple areas of the U.S., not strictly those with large Marshallese diaspora com- 


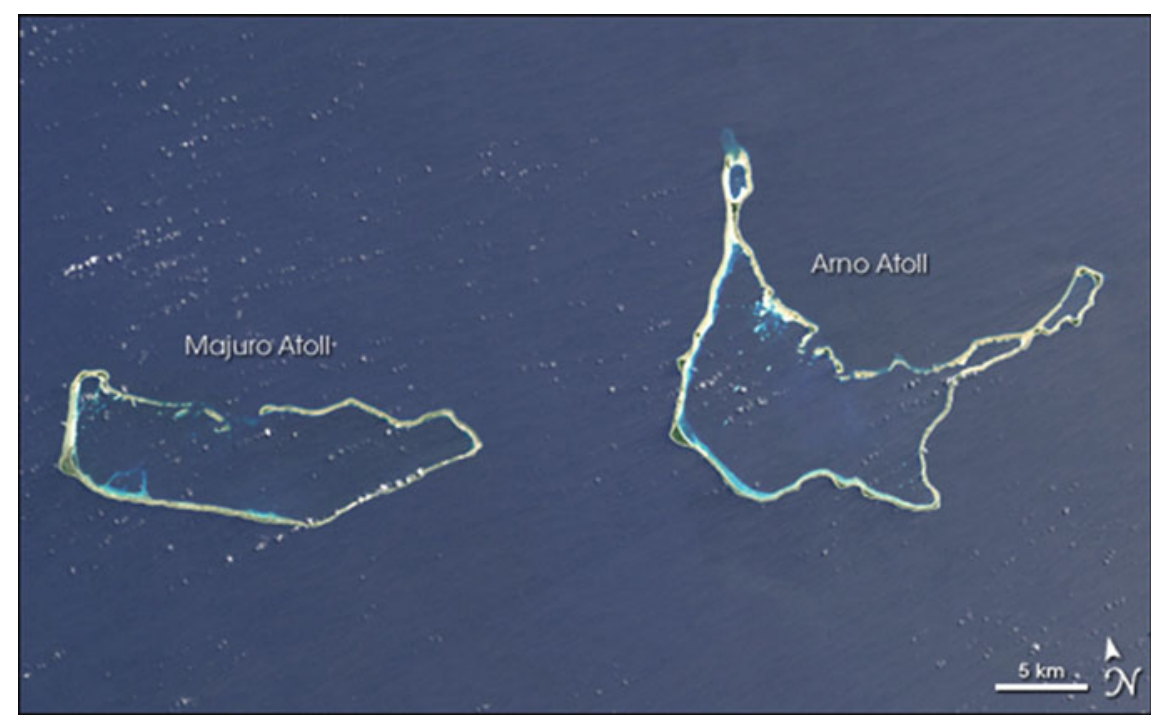

Fig. 16.1 The Republic of the Marshall Islands. Source https://visibleearth.nasa.gov/view.phpid= 8080

munities. Participants had all lived in the Marshall Islands, and currently lived in multiple locations within the United States, including Arkansas, Washington, and Ohio.

\subsection{The Marshall Islands}

The Republic of the Marshall Islands presents an important case study for understanding risks to cultural loss for low-lying islands facing relocation in the immediate future. Situated on average just $2 \mathrm{~m}$ above sea level, the 29 coral atolls and five coral islands that comprise the Marshall Islands (shown in Fig. 16.1) have little capacity to withstand even minor increases in sea level and tides. In addition to the immediate dangers of increased tides on residents' lives and property, salt-water intrusion threatens already scarce freshwater resources and warmer oceans damage the atolls' protective reefs. In the longer term, the islands face increasingly intolerable risks, leaving limited adaptive options, mainly voluntary resettlement or displacement (see also chapter by Schinko et al. 2018; Mechler and Schinko 2016).

Currently, nearly a third of the population lives outside of the Marshall Islands. These high levels of contemporary migration from the Marshall Islands can help in anticipating future challenges faced by those displaced by sea level rise. The primary destination of movement out of the RMI is the United States, due to the provisions under the Compact of Free Association (COFA). Under the COFA, the 
United States has military access to particular Marshallese islands and ocean territory, while Marshallese citizens may live, work, and study in the United States without a visa (U.S. Department of State 2016). As of the 2011 Marshall Islands census, a total of 53, 158 people lived in the Marshall Islands (Economic Policy, Planning, and Statistics Office 2011), while 22, 434 Marshallese lived in the United States. The significant proportion of Marshallese living in the United States occurred rapidly, with fewer than 7,000 Marshallese living the U.S. in 2000, increasing more than threefold by 2010 (Hixson et al. 2012). Marshallese migrants to the U.S. have settled primarily in Hawaii (33\% as of 2010), Arkansas (19.3\%), and Washington (9.8\%).

\subsubsection{Challenges}

While many relocate to Hawaii, nearly $2 / 3$ of the Marshallese in the U.S. live in geographic locations and climates, which differ markedly from the Marshall Islands, including eastern Washington state and Springdale, Arkansas. With cultural significance tied to a history of ocean navigation (including outrigger canoeing, shown in Fig. 16.2), subsistence from skilled spear-fishing, and handicrafts and local dishes made from tropical crops including banana and coconut, Marshallese face serious challenges of cultural preservation when removed from their island homes. Particularly, those interviewed commented on their families' homes and serene landscape (Fig. 16.3), aspects lacking in the U.S. context. While migrants to the U.S. can still return to the Marshall Islands to visit, they are seldom able to given the price and duration of the flight, with tickets from the mainland U.S. costing up to $\$ 2,000$ and totalling over $50 \mathrm{~h}$ in transit time. Additionally, in the event of further sea-level rise, travel to the Marshall Islands would become infeasible, resulting in the unavoidable loss of the significant physical locations and landscapes described by those interviewed. While damage to the islands would destroy many physical locations with residents have attachments to, migrants to the U.S. did indicate finding particular traditional foods like breadfruit and coconuts from local Latin American grocers, allowing for the continued consumption of traditional foods, particularly for holidays and celebrations. In addition, Marshallese can still send and receive packages fairly easily, as the US postal service operates in the RMI. This allows migrants to the U.S. to receive traditional clothing and handicrafts even while living the abroad. In the absence of continued family ties to the islands, however, this mechanism of cultural preservation would no longer be possible, requiring production of these items outside of the Marshall Islands if materials are accessible.

In addition to geographic differences, Marshallese in the U.S. face a very different social structure than that, which exists on the remote Pacific atolls. Marshallese families generally live in extended family households, lacking linguistic distinctions between mothers and aunts, siblings and cousins. Even when families do live in separate houses, children often move back and forth between households, cared for by parents, aunts, uncles, and grandparents. This fluidity of family and guardian 


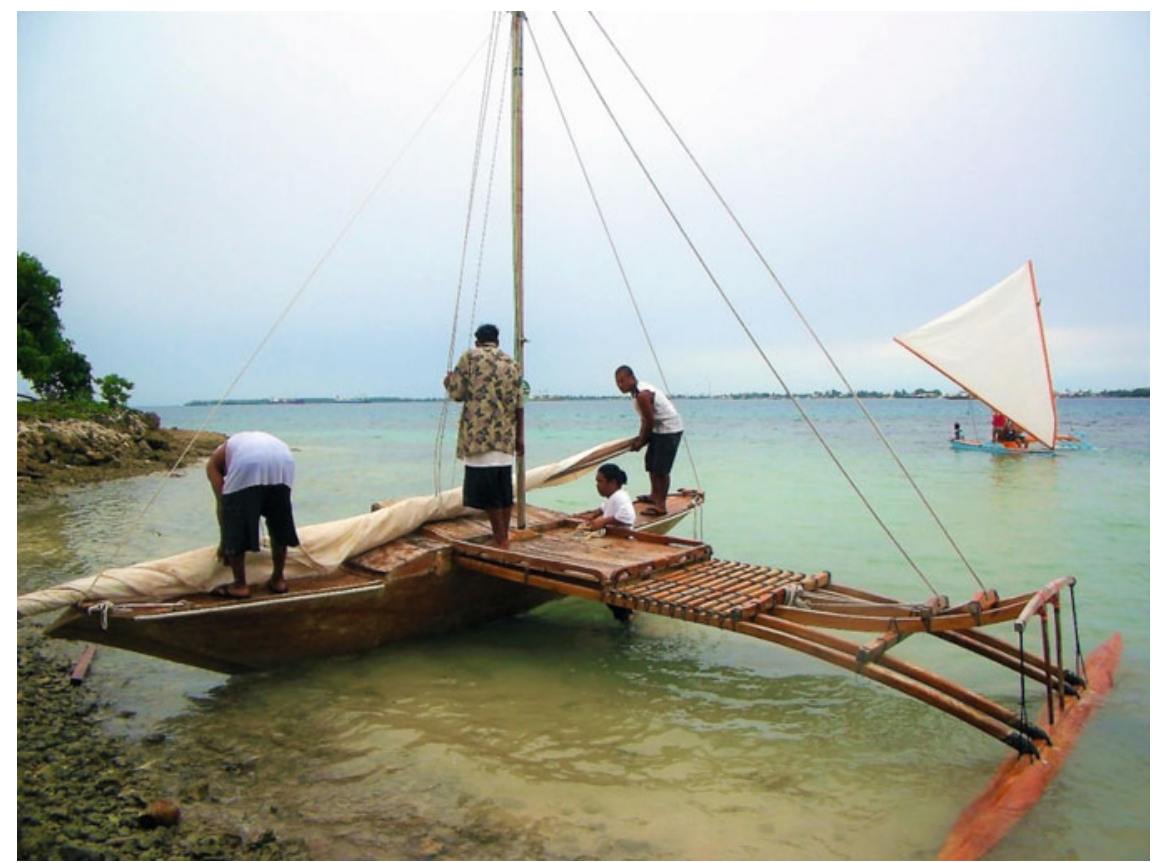

Fig. 16.2 Outrigger Canoe traditionally used in ocean navigation, Majuro Atoll, Republic of the Marshall Islands. Photo A. Heslin

distinctions differs rather sharply from the U.S. norm of single-family households, as well as the legal guardianship afforded to biological parents.

The relocation of Marshallese to particular communities in the U.S., however, does allow for continued community support. Springdale, Arkansas and Seattle, Washington for example, have large Marshallese communities, with Marshallese churches and cultural events. While a location like Arkansas is lacking many of the meaningful geographic components of maintaining island culture, the presence of a large Marshallese community was noted to maintain aspects of the language and culture. Interview respondents in Arkansas and Washington indicated having Marshallese friends in their communities and attending Marshallese celebrations on holidays. The capacity for Marshallese migrants to maintain certain aspects of their culture, including language, religious practices, and holiday celebrations is tied to access to Marshallese communities. Support for these activities and cultural centres can stem the avoidable cultural losses for these activities not explicitly tied to the physical landscape. 


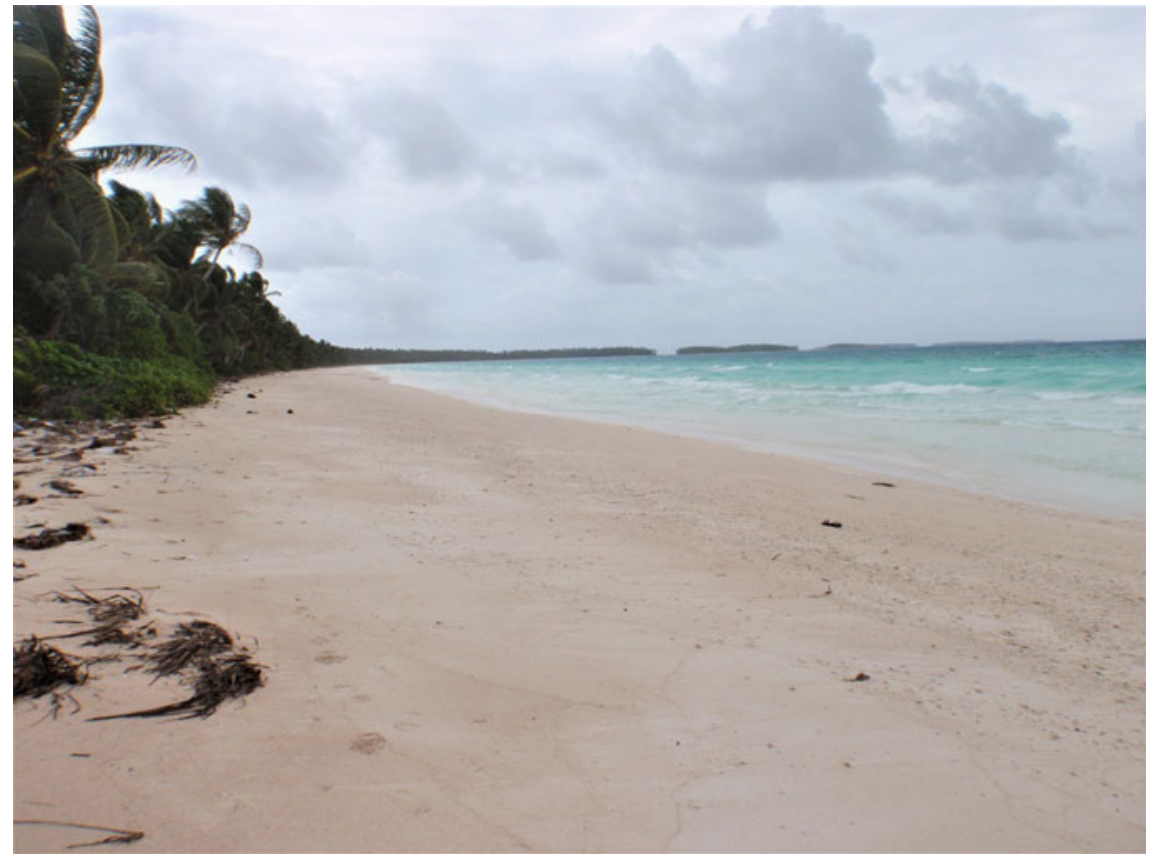

Fig. 16.3 Typical landscape, Arno Atoll, Republic of the Marshall Islands. Photo A. Heslin

\subsubsection{Opportunities}

While an involuntary relocation of the Marshall Islands' population would mark a tragic and regrettable failure of the global community in addressing climate change, the established diaspora community in the United States offers some opportunities to the Marshallese community. Marshallese migration to the U.S. has afforded employment and education opportunities not available in the RMI, as evidenced by the large-scale migration that has occurred over the past 20 years. Migration to the U.S. offers an alternative to many challenges faced in the RMI, which include scarce opportunities for employment, with remittances from the U.S. totalling an estimated 25 million dollars in 2015 (Pew Research Center 2016). Additionally, population growth has increased the need for imported foods in the RMI. This reliance on imported food, and the consumption of the least expensive imported options, has caused serious health consequences in the Marshall Islands, with over 20\% of the population suffering from diabetes and over two-thirds being overweight or obese (Ichiho et al. 2013; World Health Organization 2016). Migration to the U.S. offers access to additional medical services, though at a substantially higher cost than those in the RMI. One must view the opportunity for additional employment and healthcare within the context of the RMI's history, as many health and economic maladies suffered by Marshallese can be traced back to international involvement in the Mar- 
shall Islands - as a location of conflict, recipient of food aid, site of nuclear testing, and base for the U.S. military (Ahlgren et al. 2014).

\subsection{Conclusions}

Severe damage to the Marshall Islands would result in an irreversible loss of culturally and personally significant locations and activities. The geography of the Marshall Islands is so uncommon, that the possibility for relocating populations to similar landscapes, which would limit the cultural loss, seems almost impossible. While many geographically tied cultural practices face irreversible loss, the sizable and established population base in the United-States provides an opportunity for some cultural preservation outside of the RMI. Marshallese residents in the U.S. can continue to speak Marshallese, eat Marshallese foods, and spend time with the Marshallese communities when living in a city with a Marshallese population. With many established family and friendship ties to people living in the United States, the cultural transition involved in moving could occur more smoothly. Many current Marshallese residents in the U.S. indicate having moved to join family or staying with family when first arriving in the U.S. The possibility of this form of relocation on a larger scale, however, requires the continued terms of the Contract of Free Association, which has allowed for free movement between the two countries since the 1980s. Additionally, should migration become permanent and irreversible, the political circumstances of Marshallese residents in the U.S. would need engagement, as they currently lack guaranteed access to certain federal social programs afforded to U.S. citizens, including Medicaid, as well as representation in government.

\section{References}

Ahlgren I, Yamada S, Wong A (2014) Rising oceans, climate change, food aid, and human rights in the Marshall Islands. Health Human Rights J 16(1):69-80

Asian Development Bank (2013) The economics of climate change in the Pacific. Asian Development Bank, Manila

Barnett J, Adger WN (2003) Climate dangers and atoll countries. Clim Change 61(3):321-337

Barnett J (2011) Dangerous climate change in the Pacific Islands: food production and food security. Reg Environ Change 11(1):229-237

Brown RPC, Connell J (2004) The migration of doctors and nurses from South Pacific Island Nations. Soc Sci Med 58(11):2193-2210

Economic Policy, Planning, and Statistics Office (2011) The RMI 2011 census of population and housing summary and highlights only. Majuro, Marshall Islands

Handmer J, Nalau J (2018) Understanding loss and damage in Pacific Small Island developing states. In: Mechler R, Bouwer L, Schinko T, Surminski S, Linnerooth-Bayer J (eds) Loss and damage from climate change. Concepts, methods and policy options. Springer, Cham, pp 365-381 
Hixson L, Hepler BB, Kim MO (2012) The native Hawaiian and other Pacific Islander population: 2010. United States Census Bureau

Ichiho HM, Seremai J, Trinidad R, Paul I, Langidrik J, Aitaoto N (2013) An assessment of noncommunicable diseases, diabetes, and related risk factors in the Republic of the Marshall Islands, Kwajelein Atoll, Ebeye Island: a systems perspective. Hawaii J Med Public Health 72(5 Suppl 1):77-86

IPCC (2013) Climate change 2013: the physical science basis. In: Stocker TF, Qin D, Plattner G-K, Tignor M, Allen SK, Boschung J, Nauels A, Xia Y, Bex V, Midgley PM (eds) Contribution of working group I to the fifth assessment report of the intergovernmental panel on climate change. Cambridge University Press, Cambridge, United Kingdom and New York, NY, USA, 1535 pp

Mechler R, Schinko T (2016) Identifying the policy space for climate loss and damage. Science 354(6310):290-292

Nurse LA, McLean RF, Agard J, Briguglio LP, Duvat-Magnan V, Pelesikoti N, Tompkins E, Webb A (2014) Small Islands. In: Barros VR, Field CB, Dokken DJ, Mastrandrea MD, Mach KJ, Bilir TE, Chatterjee M, Ebi KL, Estrada YO, Genova RC, Girma B, Kissel ES, Levy AN, MacCracken S, Mastrandrea PR, White LL (eds) Climate change 2014: impacts, adaptation, and vulnerability. Part B: regional aspects. Contribution of working group II to the fifth assessment report of the intergovernmental panel on climate change. Cambridge University Press, Cambridge UK, pp $1613-1654$

Patel SS (2006) Climate science: a sinking feeling. Nature 440(7085):734-736

Pew Research Center (2016) Remittance flows worldwide in 2015

Rosegrant MW, Dey MM, Valmonte-Santos R, Chen OL (2016) Economic impacts of climate change and climate change adaptation strategies in Vanuatu and Timor-Leste. Marine Policy 67:179-188

Schinko T, Mechler R, Hochrainer-Stigler S (2018) The risk and policy space for loss and damage: integrating notions of distributive and compensatory justice with comprehensive climate risk management. In: Mechler R, Bouwer L, Schinko T, Surminski S, Linnerooth-Bayer J (eds) Loss and damage from climate change. Concepts, methods and policy options. Springer, Cham, pp 83-110

Serdeczny O (2018) Non-economic loss and damage and the Warsaw international mechanism. In: Mechler R, Bouwer L, Schinko T, Surminski S, Linnerooth-Bayer J (eds) Loss and damage from climate change. Concepts, methods and policy options. Springer, Cham, pp 205-220

Terry JP, Chui TFM (2012) Evaluating the fate of freshwater lenses on atoll islands after eustatic sealevel rise and cyclone-driven inundation: a modelling approach. Global Planet Change 88:76-84

U.S. Department of State (2016) U.S. Relations with Marshall Islands. Bureau of East Asian and Pacific Affairs

World Health Organization (2016) Marshall Islands. Diabetes Country Profiles 
Open Access This chapter is licensed under the terms of the Creative Commons Attribution 4.0 International License (http://creativecommons.org/licenses/by/4.0/), which permits use, sharing, adaptation, distribution and reproduction in any medium or format, as long as you give appropriate credit to the original author(s) and the source, provide a link to the Creative Commons license and indicate if changes were made.

The images or other third party material in this chapter are included in the chapter's Creative Commons license, unless indicated otherwise in a credit line to the material. If material is not included in the chapter's Creative Commons license and your intended use is not permitted by statutory regulation or exceeds the permitted use, you will need to obtain permission directly from the copyright holder. 